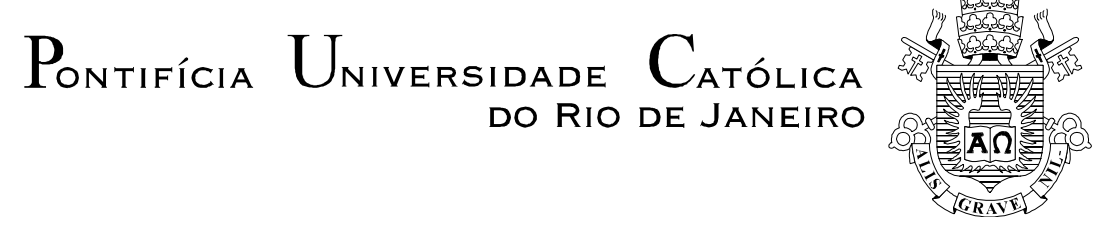

Carla do Nascimento Santos Morani

\title{
A supervisão de estágio e o processo de trabalho do assistente social
}

Dissertação apresentada como requisito parcial para obtenção do grau de Mestre pelo Programa de Pós-Graduação em Serviço Social do Departamento de Serviço Social do Centro de Ciências Sociais da PUC-Rio.

Orientadora: Prof ${ }^{a}$. Inez Terezinha stampa 


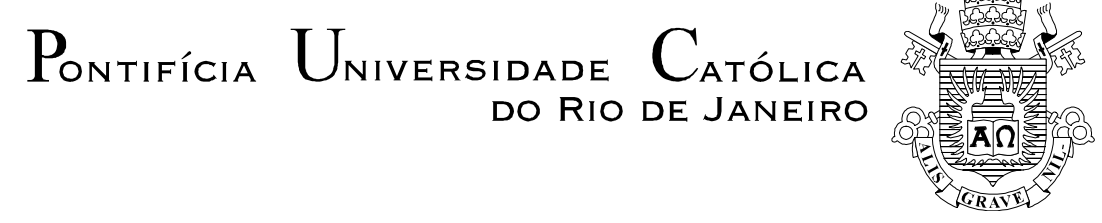

Carla do Nascimento Santos Morani

\title{
A supervisão de estágio e o processo de trabalho do assistente social
}

Dissertação apresentada como requisito parcial para obtenção do grau de Mestre pelo Programa de Pós-Graduação em Serviço Social da PUC-Rio. Aprovada pela Comissão Examinadora abaixo assinada.

\author{
Prof $^{a}$. Inez Terezinha Stampa \\ Orientadora \\ Departamento de Serviço Social - PUC-Rio \\ Prof $^{a}$. Maria Helena de Souza Tavares \\ Departamento de Serviço Social - PUC-Rio
}

Prof $^{\mathrm{a}}$. Elaine Marlova Venzon Francisco

UERJ

Monica Herz

Vice-Decana de Pós-Graduação do Centro de Ciências Sociais - PUC-Rio.

Rio de Janeiro, 09 de abril de 2010. 
Todos os direitos reservados. É proibida reprodução total ou parcial do trabalho sem autorização da universidade, da autora e da orientadora.

\section{Carla do Nascimento Santos Morani}

Graduo-se em Serviço Social pela Universidade do Grande Rio - UNIGRANRIO, em 2007. É professora da UNIGRANRIO - Prof. José de Souza Herdy e assistente social, preceptora de estágio no Laboratório de Extensão e Organização de Experiências em Políticas Sociais e Serviço Social da UNIGRANRIO. Tem experiência na área de Serviço Social, com ênfase na àrea da criança e adolescente, educação, supervisão de estágio, bem como em atividades socio-educativas e formulação de programas e projetos sociais.

Ficha Catalográfica

Morani , Carla do Nascimento Santos

A supervisão de estágio e o processo de trabalho do assistente social / Carla do Nascimento Santos Morani ; orientadora: Inez Terezinha Stampa. - 2010.

297 f. : il. (color.) ; $30 \mathrm{~cm}$

Dissertação

(Mestrado)-Pontifícia

Universidade Católica do Rio de Janeiro, Departamento de Serviço Social, Rio de Janeiro, 2010.

Inclui bibliografia

1. Serviço social - Teses. 2. Trabalho. 3. Processo de trabalho. 4. Supervisão de estágio. 5. Formação profissional. I. Stampa, Inez Terezinha. II. Pontifícia Universidade Católica do Rio de Janeiro. Departamento de Serviço Social. III. Título. 
Para minha mãezinha e para meu paizinho, amores da minha vida e razão do meu viver. 


\section{Agradecimentos}

Aos meus pais pela compreensão nos momentos de ausência, e por não poder darlhes a atenção merecida no decorrer destes dois anos. Amores da minha vida.

Ao meu esposo, pelo amor, amizade e companheirismo. Pela paciência em ouvir as minhas "idéias" sobre o tema da pesquisa e sobre os conteúdos das disciplinas cursadas no Mestrado. E por compreender os meus momentos de ausência em festas e confraternizações de amigos.

A Marina Amoedo da Costa, pelos incentivos iniciais e por acreditar no meu potencial e no meu profissionalismo. Sou grata, também, pelas "broncas" dadas no momento em que estava cursando a graduação em Serviço Social. Elas contribuíram muito para o meu desenvolvimento profissional. Aliás, vêm contribuindo!

À PUC-Rio, pelos auxílios concedidos, sem os quais este trabalho não teria se realizado.

A minha orientadora, pela aprendizagem, compromisso, parceria na realização deste trabalho e pelo acolhimento. Um exemplo de profissional que levarei para o resto da minha vida.

Ao professor Ney Luiz Teixeira e a professora Maria Helena de Souza Tavares, pelas contribuições dadas durante a qualificação do projeto de pesquisa.

A minha amiga Adriana Alice Gomes, pelo ombro amigo nos momentos difíceis que passei no decorrer do curso de Mestrado e no processo de construção desta dissertação. Parceira e pessoa maravilhosa.

A todos os professores e funcionários do Programa de Pós-Graduação em Serviço Social da PUC-Rio, pelos ensinamentos, profissionalismo e organização no desenvolvimento das atividades. 
A todos os colegas da turma de mestrado de 2008, por fazerem parte da minha vida. Foi muito bom conhecê-los.

Aos membros da banca examinadora, por aceitarem o convite para participar de momento tão importante para a minha formação. 


\section{Resumo}

Morani, Carla do Nascimento Santos. Stampa, Inez Terezinha (orientadora). A supervisão de estágio e o processo de trabalho do assistente social. Rio de Janeiro, 2010. 297p. Dissertação de Mestrado Departamento de Serviço Social, Pontifícia Universidade Católica do Rio de Janeiro -PUC-Rio.

Este estudo tem como objetivo analisar a supervisão de estágio como parte integrante do processo de trabalho do assistente social na contemporaneidade. Para tanto, foram levadas em conta as transformações que vêm ocorrendo no mundo do trabalho e os impactos que estas vêm trazendo para a profissão, tanto no sentido da formação como no da atuação dos assistentes sociais, bem como suas implicações para a efetivação do Projeto Ético-Político da profissão.Assim, constituem-se como elementos norteadores desta pesquisa o conhecimento e a reflexão sobre o papel da supervisão no processo de trabalho do assistente social, bem como sobre as formas de enfrentamento aos desafios impostos aos cursos de Serviço Social no que se refere à supervisão de estágio supervisionado. Por outro lado, observou-se que a supervisão e o estágio vêm recebendo impactos similares aos sofridos pela profissão em virtude das mudanças no mundo do trabalho. Especificamente, buscou-se conhecer de que forma as instituições campo de estágio do curso de Serviço Social da PUC-Rio vêm tratando a mediação entre a teoria e a prática e a política de estágio adotada pelo curso, no período 2009.1, traçando-se um perfil dos assistentes sociais supervisores de estágio. Ademais, foi necessário identificar o entendimento acerca da temática processo de trabalho, de forma a ser possível compreender como a dimensão ético-política da profissão ganha expressão no processo de supervisão e, também, de forma a contribuir para a construção de estratégias que busquem a efetivação do estágio e da supervisão nos moldes defendidos pelas diretrizes curriculares da Associação Brasileira de Ensino e Pesquisa em Serviço Social (ABEPSS). A metodologia utilizada foi a quali-quantitativa, que se compôs de estudos sobre o projeto político-pedagógico do curso de Serviço Social da PUC-Rio, além de outros documentos, bem como de entrevistas semi-estruturadas com supervisores das unidades campo de estágio. 


\section{Palavras-chave}

Trabalho; processo de trabalho; Serviço Social; supervisão de estágio; formação profissional. 


\section{Abstract}

Morani, Carla do Nascimento Santos. Stampa, Inez Terezinha (Advisor). The internship supervision and the labor process of social workers. Rio de Janeiro, 2010. 297p. Master's Thesis - Departamento de Serviço Social, Pontifícia Universidade Católica do Rio de Janeiro - PUC-Rio.

This study has as its objective to analyze the internship supervision as an integrant part of the labor process of the social assistant nowadays. To achieve this we took in consideration the transformations that are occurring in the world of the work and its consequences for the Social Work as much as in the sense of the graduation of social workers as in the sense of the performance of these professionals. Thus the comprehension and the reflection about de internship supervision and the challenges that the Social Work faces nowadays are central aspects of this study. On the other hand, it was possible to observe that the internship and its supervision are suffering similar impacts of those suffered by the Social Work in reason of the transformations that are occurring in world of work. Specifically we sought to know how the training fields of the PUC-Rio Social Work course are addressing the question of the mediation between theory and practical application in the context of the internship policy adopted in the first semester of the year 2009. Therefore we traced profiles of the internship supervisors and it was also necessary to identify the comprehension about the theme labor process. That was accomplished in such way that was possible to understand how the ethical-political dimension of the profession is expressed in the supervision process and also as a contribution for the construction of new strategies in the direction pointed out by the curricular directives of the Associação Brasileira de Ensino e Pesquisa em Serviço Social (ABEPSS). The methodology was qualitative and quantitative and we used interviews as well as documental analysis.

\section{Keywords}

Work; labor process; Social Work; internship supervision; profissional trainning. 


\section{Sumário}

1. Introdução

2. Trabalho e processos de trabalho no modo de produção capitalista

3. O Serviço Social na divisão social do trabalho

46

4. O processo de trabalho do assistente social na contemporaneidade: análise do processo de trabalho dos supervisores de estágio do curso de Serviço Social da PUC Rio

5. A supervisão de estágio no processo de trabalho do assistente social - as diretrizes curriculares e a dimensão ético-política da profissão no processo de ensino-aprendizagem do curso de Serviço Social da PUC-Rio

6. Considerações finais

7. Referências

8. Anexos

8.1. Anexo I - Roteiro de entrevista

8.2. Anexo II - Projeto Pedagógico do Curso de Serviço Social da PUC-Rio

8.3. Anexo III - Grade curricular do curso de Serviço Social da PUC-Rio

8.4. Anexo IV - Diretrizes curriculares da ABEPSS de 1996209

8.5. Anexo V - Diretrizes curriculares ABEPSS de 1999

8.6. Anexo VI - Resolução CFESS no 533/2008 243

8.7. Anexo VII - Política Nacional de Estágio da ABEPSS 251

8.8. Anexo VIII - Código de Ética do Assistente Social de 1993273

8.9. Anexo IX - Política Nacional de estágio (Lei 11.788 de 2008) 


\section{Lista de Siglas}

ABAS (Associação Brasileira de Assistentes Sociais)

ABESS (Associação Brasileira de Ensino em Serviço Social )

ABEPSS (Associação Brasileira de Ensino e Pesquisa em Serviço Social)

CBCISS (Centro Brasileiro de Cooperação e Intercâmbio de Serviços Sociais)

CEDEPSS (Centro de Documentação e Pesquisa em Políticas Sociais e Serviço Social)

CELATS (Centro Latinoamericano de Trabajo Social)

CFESS (Conselho Federal de Serviço Social)

CONCLAT (Conferência Nacional das Classes Trabalhadoras)

CRESS (Conselho Regional de Serviço Social)

CUT (Central Única dos Trabalhadores)

ENESSO (Executiva Nacional de Estudantes de Serviço Social)

LDB (Lei de Diretrizes Base da Educação Nacional)

ONGs (Organizações Não-Governamentais)

OSCIP's (Organizações da Sociedade Civil de Interesse Público)

PCB (Partido Comunista Brasileiro)

PNE (Política Nacional de Estágio)

PT (Partido dos Trabalhadores)

PUC-Rio (Pontifícia Universidade Católica do Rio de Janeiro) 


\section{Lista de Gráficos e Tabelas}

Gráfico 1 - Relação contratual de trabalho

Gráfico 2 - Perfil dos espaços de atuação dos campos de estágio do curso de Serviço Social da PUC-Rio em 2009

Gráfico 3 - Profissionais que se formaram com base no currículo de 1996 e 1999

Gráfico 4 - Experiência em outra área de atuação do Serviço Social

Gráfico 5 - Profissionais que haviam realizado pós-graduação ou outro curso de graduação

Gráfico 6 - Profissionais que haviam participado de cursos de atualização

Gráfico 7 - Conhecimento do Projeto Pedagógico e da política de estágio do curso de Serviço Social da PUC-Rio

Gráfico 8 - Sobrecarga da supervisão de estágio no processo de trabalho

Tabela 1- Distribuição dos campos de estágio do curso de Serviço Social da PUC-Rio em 2009.1 
"A tradição de todas as gerações mortas oprime como um pesadelo a mente dos vivos"

Karl Marx 